\title{
Ectopic Expression of a Bamboo SVP-Like Gene Alters Flowering Time and Floral Organs in Arabidopsis Thaliana
}

Shinan Liu

Guangxi University

Naresh Vasupalli

Zhejiang Agriculture and Forestry University

Dan Hou

Zhejiang Agriculture and Forestry University

Xinchun Lin ( $\square$ linxcx@163.com )

Zhejiang Agriculture and Forestry University https://orcid.org/0000-0003-0168-331X

\section{Research Article}

Keywords: Phyllostachys violascens, PvSVP2, flowering time, ectopic expression, functional analysis, E. coli

Posted Date: January 18th, 2022

DOI: https://doi.org/10.21203/rs.3.rs-1245022/v1

License: (9) This work is licensed under a Creative Commons Attribution 4.0 International License. Read Full License 


\section{Abstract}

The Short Vegetative Phase (SVP) gene is a key regulator for floral transition and development. Although SVP-like genes have been identified and characterized in many plant species, their orthologs in bamboo have not been characterized. In this study, one SVP homolog was isolated from lei bamboo based on the P. edulis transcriptome database and designated as PVSVP2. Phylogenetic analysis showed that PVSVP2 was closely related to rice OsMADS47. Expression analysis revealed that PVSVP2 was widely expressed in different tissues but significantly in vegetative tissues. Moreover, it has higher transcript levels in the late stages of flower development. Overexpression of PVSVP2 in Arabidopsis thaliana caused the early flowering and abnormal floral morphologies. Further, the qRT-PCR analysis showed that the genes regulating flowering time ( $F T$ and $S O C 1)$ and flower development $(A P 1, A P 3$ and $P I)$ expressions were significantly increased in transgenic $A$. thaliana lines and correlated with PVSVP2 expression. The subcellular location of PvSVP2 in both onion epidermal cells and $A$. thaliana protoplast was localized in the nucleus and cytomembrane. Through yeast two-hybrid and BIFC assays, we identified that PvSVP2 interact with PvMADS56 (a SOC1 homolog) and PvVRN1 (an AP1 homolog). These results suggested that $P V S V P 2$ may play an essential role in the flowering process of bamboo by regulating the PVMADS56 and PVVRN1. Besides, we purified and obtained the PVSVP2 recombinant protein by prokaryotic inducement. Our data will provide information to understand the characterization and function of PVSVP2 and be beneficial to illustration the molecular mechanism of bamboo flowering.

\section{Key Message}

PVSVP2, a bamboo SVP homolog, might cause early flowering and abnormal floral organs by interacting with PvMADS56 and PvVRN1.

\section{Introduction}

The floral transition is a complex process and significantly affects both plant fitness and crop yield. Therefore studying the underlying mechanisms is vital for increasing agricultural productivity (Bouché et al. 2016). The Short Vegetative Phase (SVP) gene is a crucial flowering repressor and regulated by autonomous, thermosensitive and gibberellin pathways (Andrés et al., 2014; Hartmann et al. 2000; Lee et al. 2013; Li et al. 2008; Marín-González et al. 2015). Although SVP is widely expressed in plant stems and leaves, it can delay the floral transition by regulating integrators of flowering time signals (SOC1, FT and FLC genes) (Li et al. 2008; Jang et al. 2009; Mateos et al. 2015). The integrators integrate various environmental and endogenous signals to control the transition from vegetative to reproductive development (Bouché et al. 2016; Amasino and Michaels 2010; Parcy 2005). In addition, SVP also interacts directly or indirectly with AP1, AP3, PI and SEP3 to affect the development of floral organs (Gregis et al. 2006; de Folter et al. 2004). Therefore, SVP not only controls the flowering time but also affects flower development. 
The role of SVP genes in flower development and flowering time regulation, consistent in most of the studies. In A. thaliana, overexpression of SVP genes leads to late flowering and svp mutant plants were early flowering (Bouché et al. 2016; Li et al. 2008; Masiero et al. 2004). Ectopic expression of PtSVPfrom trifoliate orange in $A$. thaliana causes late flowering and additional trichomes and floral defects ( $\mathrm{Li}$ et al. 2010). Overexpression of two Medicago SVP genes causes floral defects and delayed flowering in $A$. thaliana (Jaudal et al. 2014). In kiwifruit, four SVP (SVP1, SVP2, SVP3 and SVP4) homologs have been identified. Among them, SVP1 and SVP3 act repressors of flowering and the overexpression studies identify that these gene was able to rescue the $A$. thaliana svp-41 mutant (Wu et al. 2012). These data show that SVP-like genes have the conserved roles in dicot species in floral development and flowering time regulation. In Antirrhinum, INCOMPOSITA (an SVP homolog) controls prophyll development, floral meristem identity and flowering time (Masiero et al. 2004).

In contrast, SVP homologs from monocots mainly regulate flower development instead of flowering time. In barley (Hordeum vulgare), ectopic expression of Barley MADS1 (BM1) and BM10 (SVP homologs) inhibit floral development and cause floral reversion (Trevaskis et al. 2007). There are three SVP-like genes (OsMADS22, OsMADS47 and OsMADS55) in rice (Lee et al. 2008a). Further, transgenic rice overexpressing OsMADS22 have abrupt floral morphogenesis (a disorganized palea, an elongated glume and a two-floret spikelet) (Sentoku et al. 2005). Heterologous expression of OsMADS22 and OsMADS47 in $A$. thaliana only causes the alternation of flower development but not complement for the flowering phenotypes of svp mutant (Fornara et al. 2008). However, overexpression of OsMADS55 delays the flowering time of wild-type plants and rescues the early flowering phenotype of svp mutant in $A$. thaliana (Lee et al. 2012). Above results indicated that SVP homologs in plants were mulfuctional genes along with conservative and divergent characteristics.

Bamboo is the woody monocot that belongs to the grass family Poaceae (Hou et al. 2021). However, bamboo is semelparous and owns many peculiar habits in flowering (Lin and Mao 2007). Bamboo flowering has a long vegetative phase and is unpredictable. Further, the flowering intervals vary from a few years to several decades (Sharma et al. 2014; Yao et al. 2020; Zheng et al. 2020). The flowering is often followed by the death of the flowered clumps (Lin and Mao 2007; Hou et al. 2020). The gregarious bamboo flowering results in substantial economic loss and ecological crisis in many tropical and subtropical regions. The mechanism of bamboo flowering is still unknown, even if this phenomenon has been recorded and studied for a long time. The SVP-like genes from monocots and dicots play an important role in the regulation of flowering. However, the molecular characteristics of bamboo SVP-like genes and their functions are still unclear. In this study, an SVP-like gene from lei bamboo (Phyllostachys violascens) was cloned and characterized by analyzing the overexpression plants of transgenic $A$. thaliana. Our study will lay a foundation to understand the mechanism of bamboo flowering.

\section{Materials And Methods}

\section{Plant material and growth conditions}


Lei bamboo samples used for gene cloning and expression analysis were collected in the Bamboo Garden of Zhejiang A and F University. Wild-type A. thaliana Columbia-0 (Col-0) was used for gene transformation. Seeds were sterilized with $10 \%$ sodium hypochlorite $(\mathrm{NaClO})$ and washed five times with $\mathrm{ddH}_{2} \mathrm{O}$, and then sowed onto $1 / 2 \mathrm{MS}$ petri dish. The $A$. thaliana seedlings were transplanted into the soil when they grew four cotyledons. All $A$. thaliana plants grow at $22^{\circ} \mathrm{C}$ under a long photoperiod (16h light /8h dark) in a control growth chamber.

\section{Isolation of PvSVP2 from Lei bamboo}

Total RNA was extracted from the young leaf using Trizol reagent (Invitrogen, US). RNA quality and concentration were detected with $1 \%$ RNase-free agarose/ethidium bromide gels and spectrophotometer. First-strand cDNA was synthesized by using Reverse Transcriptase M-MLV (TAKARA Company). The sequence of OSMADS55 and OsMADS47 (SVP homolog from rice) ORF were blasted on the moso bamboo (P. edulis) transcriptome database (Peng et al. 2013) by BioEdit software and isolated the PVSVP1 (data not show in this paper) and PVSVP2 genes. Full-length sequences were amplified using gene-specific primers of PVSVP2 (Table S1). The PCR product was cloned into a pMD20-T vector (Takara Company) and then sequenced for further verification.

\section{Plasmid construction and transformation of $A$. thaliana}

To construct the overexpression vector, the ORF of PVSVP2 was ligated to the Kpnl-Sall site of the pCAMBIA1302 vector under the control of cauliflower mosaic virus (CaMV) 35S promoter. The pCAMBIA1302-PVSVP2 fusion vector wastransformed into Agrobacterium tumefaciens strain GV3101 cells and then were introduced into $A$. thaliana (ecotype Col-0) using the floral dip method (Clough and Bent 1998). Transgenic seeds were survived in the medium containing $50 \mu \mathrm{g} / \mathrm{ml}$ hygromycin were transferred to soil and further confirmed by genomic PCR. Screened as above, positive $\mathrm{T}_{3}$ generation of 35S:::PVSVP2 transgenic $A$. thaliana were used for further study. The flowering time of $A$. thaliana was scored as rosette leaf number and days in which the main stem bolted $1 \mathrm{~cm}$.

\section{Gene expression analyses}

Quantitative real-time PCR(qRT-PCR)was used to analyze the spatio-temporal expression of PVSVP2. Total RNA was extracted from different tissues, including young leaf, mature leaf, culm, rhizome, shoot or flower, and at three times (young leaf and flower) as described by Liu et al. (2016) in flowering and nonflowering plants and healthy leaves of wild-type and $T_{3}$ homozygous transgenic plants. qRT-PCR reactions were performed in CFX96 Real-Time PCR Detection System (Bio-Rad, Germany) with SYBR Premix Ex Taq II mix (Takara). The PCR conditions were as follows: $95^{\circ} \mathrm{C}$ for 3 min, followed by 40 cycles of amplification $\left(95^{\circ} \mathrm{C}\right.$ for $10 \mathrm{sec}, 60^{\circ} \mathrm{C}$ for $20 \mathrm{sec}$ ). Reactions were performed in $20-\mu \mathrm{L}$ mixtures consisting of $10 \mu \mathrm{L} 2 \times$ SYBR Premix Ex Taq II mix, $0.5 \mu \mathrm{L}$ each forward or reverse primer, $1 \mu \mathrm{L}$ cDNA template and $8 \mu \mathrm{L} \mathrm{ddH_{2 }} \mathrm{O}$. The PheUBC18 gene from moso bamboo was used as the control for normalization (Qi et al. 2013) for different tissues expression analyses. The primers are listed in Table S1. 
Further, FLC, FT, SOC1, AP1, AP3 and PI genes expressions were also analyzed by gene-specific primers (Table S1) in wild-type and $\mathrm{T}_{3}$ homozygous transgenic plants. The actin1 was used as an internal control. The relative gene expression levels were calculated using the $2^{-\Delta \Delta C t}$ method (Livak and Schmittgen 2001).

\section{Subcellular localization}

To determine the subcellular location, the coding sequences of PVSVP2 without TAG at the 3 ' end was ligated to the BamHFSall site of the vector Cam35S-gfp to generate a 35S::PvSVP2-GFP fusion vector. The plasmid 35S::PvSVP2-GFP was transfected into onion epidermal cells by particle bombardment method (Wang et al.1988) and $A$. thaliana protoplasts by the polyethylene glycol (PEG) as described by Yoo et al.(2007). Meanwhile, the transient expression of the empty vector (Cam35S-gfp) was used as a positive control. The corresponding fluorescence images were taken using a confocal laser scanning microscope (LSM510, Zeiss, Germany).

\section{Yeast two-hybrid assay}

The coding sequences of PVSVP2, PVMADS56 and PVVRN1 were amplified with specific primers (Table S1) and cloned into the pGADT7 (AD) and pGBKT7 (BD) plasmids. All the constructs were verified by sequencing. According to the manufacturer's instructions, the prey pGADT7 vector and constructs ADPvSVP2, AD-PvVRN1, and AD-PvMADS56 were transformed into yeast strain Y2H Gold, and the bait pGBKT7 vector and constructs BD-PvSVP2, BD-PvVRN1, BD-PvMADS56 were transformed into yeast strain $\mathrm{Y} 187$. The transformed yeast cells were incubated at $30^{\circ} \mathrm{C}$ for $3-5$ days on the selection medium SD/-Leu/X-a-gal and SD/-Trp/ X-a-gal for autoactivation. The cells that do not develop blue were confirmed as they do not contain autoactivation. The pGBKT7-53 + pGADT7-T and pGBKT7-Lam+ pGADT7-T were positive and negative controls, respectively. The protein interactions were confirmed on $\mathrm{SD} /$-Trp/-Leu/-His/-Ade/ X-a-gal medium.

\section{Bi-molecular fluorescence complementation (BIFC) analysis}

The coding sequences of PVSVP2, PVVRN1 and PVMADS56 genes were cloned into pSAT1-nEYFP-C1 (nYFP) and pSAT4-cEYFP-C1(B) (cYFP) to generate PvSVP2-cYFP, PvVRN1-nYFP, PvMADS56-nYFP constructs. Protoplasts were isolated from the leaves of three-week-old $A$. thaliana plants. The pair plasmids of PvSVP2-cYFP/PvVRN1-nYFP, and PvSVP2-cYFP /PvMADS56-nYFP were cotransformed into $A$. thaliana protoplasts based on the polyethylene glycol (PEG) mediated transformation method described by Yoo et al. (2007). The plasmid combinations PvSVP2-cYFP/ pSAT1-nYFP, pSAT4cYFP/PvVRN2-nYFP, pSAT4-cYFP /PvMADS56-nYFP were used as controls. The transformed cells images were captured after $20 \mathrm{~h}$ incubation in a confocal laser scanning microscopy (LSM510, Zeiss, Germany) at $488 \mathrm{~nm}$ excitation and $594 \mathrm{~nm}$ emission was observed.

\section{Prokaryotic expression and purification of PVSVP2}


The open reading frame of $P V S V P 2$ was amplified using pMD19-PVSVP2 plasmid as the template and then linked to the BamHI-Sall site of the vectorpET -HTT (pHTT) to form a PVSVP2-pHTT fusion vector. The positive PVSVP2-pHTT construct was transformed into E.coli Rossetta TM (DE3) cell for protein production. The cells were cultivated in Luria-Bertani (LB) media containing $1 \%$ tryptone, $0.5 \%$ yeast extract, $1 \% \mathrm{NaCl}$ and $50 \mathrm{mg} / \mathrm{ml}$ kanamycin. $10 \mathrm{ml}$ bacteria was further inoculated into $1 \mathrm{~L}$ LB culture at 37 ${ }^{\circ} \mathrm{C}$ for $220 \mathrm{r} / \mathrm{m}$ until the OD600 reached to $0.5-0.6$. Isopropyl-thiogalactoside (IPTG) was added with a final concentration of $400 \mu \mathrm{mmol} / \mathrm{L}$ while no IPTG as a control. Then the bacteria were induced under $37^{\circ} \mathrm{C}$ and $20^{\circ} \mathrm{C}$ for $5 \mathrm{~h}$ and $12 \mathrm{~h}$, respectively. The cells were centrifuged at $5000 \times \mathrm{g}$ for $10 \mathrm{~min}$. The collected precipitates were disrupted in lysis buffer with a 10 min sonication at amplitude of $35 \%$ power (on/off $8 / 6$ s). Then the supernatants and precipitates were separately collected and were detected by $12 \%$ sodium dodecylsulfate-polyacrylamide gel electrophoresis (SDS-PAGE).

Next, the PvSVP2-pHTT fusion protein was purified from the supernatant using the Dextrin Sepharose High performance (GE Company, Shanghai). The supernatant was added to $2 \mathrm{ml}$ Nickel beads and rocked slowly on ice for $1 \mathrm{~h}$ after washing Nickel beads with the sterile distilled water and lyse buffer successively. The Nickel beads were then washed with 15 column volumes (CV) of lysis buffer with $40 \mathrm{mmol} / \mathrm{L}$ concentration. PvSVP2 protein was further eluted by $15 \mathrm{CV}$ of lysis buffer, including $40 \mathrm{mmol} / \mathrm{L}$ imidazole. The eluents were collected and analyzed by $12 \%$ SDS.

\section{Bioinformatics and statistical analyses}

The amino acid sequences of related SVP-like proteins used in phylogenetic tree construction were retrieved from the NCBI database. Phylogenetic analysis was constructed in the MEGA 5.0 software using the Neighbor-Joining method with a bootstrap value of 1000 replications (Tamura et al. 2011). Primers were designed by the Vector NTI and Premier Primer 5 software. The software ProtParam in the ExPASy (http://exPasy.org) was used to analyze the physical and chemical properties of the protein. The subcellular localization of the protein was predicted with WoLF PSORT (http://www.genscript.com/psort/wolf_psort.html). Statistical analysis was carried out using SPSS 21.0. Differences were analyzed with one-way ANOVA followed by Tukey's test. Significance was accepted at the level of $p<0.05$ or $p<0.01$.

\section{Results}

\section{Isolation and bioinformatics analysis of PVSVP2}

We isolated two SVP-like genes PVSVP1 and PVSVP2, from $P$. violascens according to the $P$. edulis transcriptome database. However, only PVSVP2 data were shown in this paper. The PVSVP2 is $693 \mathrm{bp}$ nucleotides long, and 230 amino acids possess a MADS-box and K-box (Fig. 1a). Moreover, many DNA binding sites and dimerization interfaces were found in the MADS-box of the PvSVP2 protein (Fig. 1a). Its theoretical molecular weight (MW) and the theoretical isoelectric point (pl) were $26.02 \mathrm{KDa}$ and 7.76, respectively. Phylogenetic tree analysis showed that PVSVP2 were grouped with monocot Poaceae SVP- 
like proteins (Fig.1b). Moreover, PvSVP2 clustered as a subgroup with BM1, ZMM20 and OsMADS47, and was more closely related to OsMADS47 from 0 . sativa, with $75.1 \%$ identity (Fig.1c).

\section{Expression analysis of PVSVP2}

qRT-PCR analysis was carried out for detecting the transcript level of PVSVP2 in different tissues and developmental stages. The results showed that PVSVP2 was expressed in all tested tissues, including young leaf, mature leaf, culm, rhizome, shoot and flower (Fig. 2a). In flowering and non-flowering plants, the mRNA levels of PVSVP2 were higher in culm and rhizome, whereas lowest in the shoot. To determine whether PVSVP2 were related to flowering in P. violascens, we analyzed the expression in the leaf and flower of flowering plant (FL and FF), respectively and the leaf of the non-flowering plant (VL). These tissues were collected in three different stages $\mathrm{T} 1, \mathrm{~T} 2$ and $\mathrm{T} 3$ as described by our previous publication, Liu et al. (2016) (T1: the time when the floral bud formed and switched from the vegetative phase into the reproductive stage (March 15); T2: The time when the inner organs of the flower began to form (March 29); T3: The blooming stage when the anther was outcropped from palea (April 12)). The expression of PVSVP2 changed with the flowering stage from March 15 to April 12 (Fig. 2b). The mRNA level of PVSVP2 in FL increased first from T1 to T2, and then decreased to T3. In VL, the mRNA level of PVSVP2 was first reduced from T1 to T2 and then remained almost unchanged during T2-T3. In contrast to $\mathrm{FL}$ and $\mathrm{VL}$ samples, the mRNA level increased significantly from T1 and T2 in FF, then remained unchanged to T3. Moreover, the PVSVP2 expression in FF was lower at T1 and higher in T2 and T3 than $\mathrm{VL}$ and FL (Fig. 2b).

\section{Ectopic expression of PVSVP2 in A. thaliana caused the early flowering and abnormal floral morphologies}

To determine PVSVP2 function, we generated transgenic $A$. thaliana plants expressing PVSVP2 constitutively (35S::PvSVP2). Among eleven homologous T3 transgenic $A$. thaliana lines, we selected three lines (line 1, line 28 and 42) for further analysis. Compared with the wild-type $A$. thaliana, plants carrying 35S:::PVSVP2 vector (line1, line28, and line42) flowered significantly early by an average of 9.4 days (Fig. 3a, b, p<0.01). Further, the number of rosette leaves at the time of bolting for three 35S::PVSVP2 lines were less than the control plants with an average of 2.4 leaves (Fig. 3c, $p<0.05$ or p $<0.01)$. The qRT-PCR analysis identified that the flowering time was correlated with the PVSVP2 expression level (Fig. 3d). For example, line 28 was the earliest flowering plant among the three lines studied, containing the highest transcript level of PVSVP2. Moreover, 35S::PVSVP2 transgenic lines also produced abnormal floral organs. As follow, the sepals of transgenic plants appeared to be small and leaf-like structures (Fig. 4b, C), which did not enclose and protect inner floral parts (Fig. 4e) and kept on until the seed capsule matured (Fig. $4 \mathrm{f}, \mathrm{g}$ ). Meanwhile, the petals also displayed the opened phenotype (Fig. $4 a, b$ ). Besides, the petals of $35 S$ :: PVSVP2 transgenic lines were initially green and became purple with the flowering process (Fig. 4b, c).

PVSVP2 overexpression altered the expressions of flowering-related genes in transgenic $A$. thaliana plants 
It is well reported that SOC1, FT and FLC genes are involved in the regulation of flowering time (Li et al. 2008; Jang et al. 2009; Mateos et al. 2015). Therefore, to analyze the influence of PVSVP2 on the flowering time, transcript levels of $F T$, SOC1 and FLC genes were analyzed by qRT-PCR. Compared with the wild-type plants, in 35S.:PVSVP2 transgenic plants, FT and SOC1 transcript levels were both increased, but FLC transcript levels displayed no noticeable change (Fig. 5). These results indicate that PVSVP2 overexpression causes early flowering mainly by upregulating the $F T$ and $S O C 1$ genes in transgenic $A$. thaliana. Further, we also analyzed the $A P 1, A P 3$ and $P /$ genes, which are essential for developing flower organs (Liu et al. 2009). The AP1, AP3 and Plexpressions were highly upregulated in 35S::PVSVP2 transgenic plants compared with the wild-type plants. The qRT-PCR results indicated that $A P 1, A P 3$ and $P I$ expressions are positively correlated with $P V S V P 2$ expression in transgenic lines (Fig. 5). These results indicated that overexpression of $P V S V P 2$ in $A$. thaliana affects the development of the floral organ by modulating $A P 1, A P 3$ and $P /$ expression.

\section{PvSVP2 located in the nucleus and cytomembrane}

We predicted that the PVSVP2 was located in the nucleus by the WoLF PSORT software. Further, we confirmed the subcellular location using the particle bombardment method using onion epidermal cells. Confocal microscope images revealed that the PVSVP2-GFP fusion protein was mainly localized in the nucleus and thinly localized in the cytomembrane of the onion epidermal cells. In contrast, the empty vector was uniformly distributed throughout the whole onion cell (Fig. 6a). To further confirm this, the PvSVP2-GFP fusion vector was also transformed into the $A$. thaliana protoplasts by PEG-mediated transformation. These results also confirm that PvSVP2-GFP was positioned in the nucleus and cytomembrane of the A. thaliana protoplasts (Fig. 6b).

\section{PvSVP2 could interact with PvVRN1 and PvMADS56 in yeast two-hybrid and BIFC assays}

To further investigate the $P V S V P 2$ role in flowering, the protein-protein interaction experiments were performed between PvSVP2 and PvVRN1 (an AP1 homolog) (Ma et al. 2016) and PvMADS56 (a SOC1 homolog) (Liu et al. 2016) through yeast two-hybrid. The PvSVP2, PvVRN1 and PvMADS56 genes in pGBKT7 or pGADT7 developed white colonies in SD/-Leu/X-gal or SD/-Trp/X-gal media, respectively, suggesting that these proteins had no transcriptional activity in yeast (Fig. S1). The yeast cells cotransformed with pGBKT7-PvSVP2 + pGADT7-PvVRN1 and pGBKT7-PvSVP2 + pGADT7-PvMADS56 were able to develop blue colonies in SD/-Trp/-Leu/-His/-Ade/ X-a-gal media (Fig. 7). These results indicated the direct PvSVP2 interaction with PvVRN1 and PvMADS56 in yeast cells. Further, we confirmed these protein-protein interactions through BIFC assay. Strong YFP signals were observed in the cytoplasm of protoplasts transformed with plasmids PvSVP2-cYFP/PvMADS56-nYFP and PvSVP2-cYFP/PvVRN1nYFP (Fig. 8). BIFC experiment confirmed that PvSVP2 could interact with PvVRN1, PvMADS56 in vivo.

\section{Prokaryotic expression of PvSVP2}

We used the prokaryotic expression system to analyze PvSVP2 protein solubility. The PvSVP2-pHTT construct was induced at $37^{\circ} \mathrm{C}$ and $20^{\circ} \mathrm{C}$, respectively (Fig. 9a). SDS-PAGE analysis showed that a 
specific protein band of about $30 \mathrm{kDa}$ was expressed in supernatant at $20^{\circ} \mathrm{C}$ by IPTG induction (Fig. $9 \mathrm{a}$, lane 5). However, the molecular mass of the fusion protein was $27 \mathrm{kDa}$ including a $1 \mathrm{kDa}$ His tag protein and a $26 \mathrm{kDa}$ PvSVP2 protein. To further verify it, the soluble protein was further purified with a dextrin sepharose high performance Fig. 9b) and the protein sequence was examined by MALDI-TOF/TOF mass spectrometer analysis. As Fig. 9c shown, the generated peptides and the peptides derived from PvSVP2 protein sequence had high coverage rate, reach to $53 \%$, indicating that the protein was PVSVP2-pHTT fusion protein.

\section{Discussion}

The SVP genes play a crucial role in controlling flowering time and floral organ characteristics (Hartmann et al. 2000; Michaels et al. 2003). In this study, we isolated and characterized one SVP homolog, PVSVP2, from Lei bamboo. Phylogenetic analysis showed that PvSVP2 belonged to the same group with BM1, ZMM20 and OsMADS47 from monocot plants and was closely related to OsMADS47 (Figure 1b, c). Previous studies indicate that SVP homologs are different and have three types of expression patterns. The first type is mainly expressed in vegetative tissues but not in reproductive tissues like AtSVP (Hartmann et al. 2000), BM1 (Trevaskis et al. 2007), OsMADS47 (Lee et al. 2012) and AcSVPs (Wu et al. 2012; Wu et al. 2017); the second type is expressed in reproductive tissues but not in vegetative tissues such as OsMADS22 (Lee et al. 2012); the third type is expressed both in vegetative and reproductive tissues such as OSMADS55 (Lee et al. 2012), INCOMPOSITA (Masiero et al. 2004), MtSVP (Jaudal et al. 2014), CmSVP (Gao et al. 2017), LoSVP (Tang et al. 2020), EiSVPs (Jiang et al. 2019), MiSVPs (Mo et al. 2021) and PavSVP (Wang et al. 2021). Our results identified that PVSVP2 belongs to the third type and was expressed in all vegetative and reproductive tissues such as leaf, culm, rhizome, shoot and flower (Figure 2). These results showed that the expression pattern of SVP-like genes is various, suggesting that their function may be different in different species.

To identify its function, PVSVP2 was ectopically expressed in A. thaliana. The 35S.:PVSVP2 transgenic plants displayed abnormal sepal and petal structures (Fig. 4). These phenotypic observations were consistent with most SVP-group MADS-box genes studied. It was worth noting that the petals of these transgenic plants became purple in color. Similar phenotype was observed in $A$. thaliana transgenic plants overexpressed with the OsMADS22 gene (Fornara et al. 2008). Despite this, PvSVP2 was closely related to OsMADS47 rather than OsMADS22. For SVP homologs, most of them mainly as a repressor in regulating flowering time, but recent studies find that a few have opposite function. For example, PfMADS16 (Polypogon fugax) and MiSVP2 overexpressing in A. thaliana displayed an early flowering phenotype (Mo et al. 2021; Zhou et al. 2020). Our results also show that overexpression of PVSVP2 led to early flowering in transgenic $A$. thaliana lines (Fig. 3a-C). These results suggested that SVP-like genes have functional conservation and diversification.

Because the overexpression of PVSVP2 resulted in early flowering and abnormal organs, the transcript levels of related genes were analyzed in 35S:::PVSVP2 plants. The qRT-PCR results showed that the $F T$ and $S O C 1$ gene expression was significantly increased and positively correlated with PVSVP2 expression 
in transgenic lines (Fig. 5). These results were consistent with overexpression studies of MiSVP2 and PfMADS16 in A. thaliana, which displayed an early flowering phenotype (Mo et al. 2021; Zhou et al. 2020). But unlike MiSVP2, the expression of FLC remained unaltered in 35S::PVSVP2 transgenic plants. Moreover, $A P 1, A P 3$ or $P$ lexpressions were increased in these transgenic plants (Fig. 5). In conclusion, $P V S V P 2$ affected flowering time by regulating $F T$ and $S O C 1$ expression and flower development by regulating $A P 1, A P 3$ and $P /$ expression in transgenic $A$. thaliana plants.

In A. thaliana, SVP can interact with SOC1 or AP1 protein to regulate flowering time and to establish floral meristem identity, respectively (Gregis et al. 2008; Lee et al. 2008b). In this study, PvSVP2 could interacted with PvMADS56 and PvVRN1 as demonstrated by the yeast two-hybrid and BiFC assays (Fig. 7, 8). PVMADS56 (a SOC1 homolog) and PVVRN1 (an AP1 homolog) from P. violascens overexpressing in $A$. thaliana display not only abnormal floral organs but also caused early flowering (Liu et al. 2016; Ma et al. 2016). Therefore, we proposed that $P V S V P 2$ might affect flowering time and flower development by interacting with PVVRN1 and PVMADS56 in bamboo.

SVP and SOC1 are located in the nucleus and cytoplasm, respectively. However, SOC1-SVP heterodimers are translocated to the nucleus, suggesting SOC1 localization is affected by SVP (Lee et al. 2008b). Unlike SVP, PvSVP2 is not only located in the nucleus but also in the cytomembrane (Fig. 6). The same results are found for the subcellular location of PavSVP (Wang et al. 2021). Intriguingly, PvMADS56PvSVP2 and PvVRN1-PvSVP2 heterodimers were translocated to the cytoplasm by transient assays, whereas PvMADS56 and PvVRN1 are also located in the nucleus (Fig. 8) (Liu et al. 2016; Ma et al. 2016). These data suggested that PVSVP2 was different from SVP in signal transduction and needed a further study for confirmation. Besides, with the success of prokaryotic expression in this paper, these results will be helpful for further functional research of $P V S V P 2$ in bamboo.

\section{Declarations}

Author contribution statement Shina Liu designed and performed all the experiments and write the manuscript. Naresh Vasupalli andDan Hou revised the manuscript. Xinchun Lin designed the experiments and revised the manuscript.

Funding Our work was funded by National Natural Science Foundation of China (31971735), the Natural

Science Foundation of Zhejiang Province (LZ20C160002) and the State Key Laboratory of Subtropical Silviculture (ZY20180203).

Conflicts of interest The authors declare no conflict of interest.

\section{References}

1. Amasino RM, Michaels SD (2010) The Timing of Flowering. Plant Physiol 154: 516-520

2. Andrés F, Porri A, Torti S, Mateos J, Romera-Branchat M, García-Martínez JL, Fornara F, Gregis V, Kater MM, Coupland G (2014) SHORT VEGETATIVE PHASE reduces gibberellin biosynthesis at the 
Arabidopsis shoot apex to regulate the floral transition. PANS 111: E2760-E2769

3. Bouché F, Lobet G, Tocquin P, Périlleux C (2015) FLOR-ID: An interactive database of flowering-time gene networks in Arabidopsis thaliana. Nucleic Acids Res 44: D1167-D1171

4. de Folter S, Immink RGH, Kieffer M, Pařenicová L, Henz SR, Weigel D, Busscher M, Kooiker M, Colombo L, Kater MM, Davies B, Angenent GC (2005) Comprehensive Interaction Map of the Arabidopsis MADS Box Transcription Factors. The Plant Cell 17: 1424-1433

5. Fornara F, Gregis V, Pelucchi N, Colombo L, Kater M (2008) The rice StMADS17-like genes OsMADS22 and OsMADS47 cause floral reversions in Arabidopsis without complementing the svp and ag/24 mutants. J Exp Bot 59: 2181-219

6. Gao Y, Gao Y, Fan M, Yuan L, Wu Z, Zhang Q (2017) Overexpression of Chrysanthemum morifoliumSVP gene delays blossoming and regulates inflorescence architecture in transgenic Arabidopsis. Can J Plant Sci 97: 1130-1139

7. Gregis V, Sessa A, Colombo L, Kater MM (2006) AGL24, SHORT VEGETATIVE PHASE, and APETALA1 Redundantly Control AGAMOUS during Early Stages of Flower Development in Arabidopsis. The Plant Cell 18: 1373-1382

8. Gregis V, Sessa A, Colombo L, Kater MM (2008) AGAMOUS-LIKE24 and SHORT VEGETATIVE PHASE determine floral meristem identity in Arabidopsis. The Plant J 56: 891-902

9. Hartmann U, Hohmann S, Nettesheim K, Wisman E, Saedler H, Huijser P (2000) Molecular cloning of SVP: a negative regulator of the floral transition in Arabidopsis. The Plant $\mathrm{J} 21: 351-360$

10. Hou D, Li L, Ma T, Pei J, Zhao Z, Lu M, Wu A, Lin X (2021) The SOC1-like gene BoMADS50 is associated with the flowering of Bambusa oldhamii. Horticulture Research 8: 1-13

11. Hou D, Zhao Z, Hu Q, Li L, Vasupalli N, Zhuo J, Zeng W, Wu A, Lin X (2020) PeSNAC-1, a NAC transcription factor from moso bamboo (Phyllostachys edulis) confers tolerance to salinity and drought stress in transgenic rice. Tree Physiol 40: 1792-1806

12. Jang S, Torti S, Coupland G (2009) Genetic and spatial interactions between FT, TSF and SVP during the early stages of floral induction in Arabidopsis. The Plant J 60: 614-625

13. Jaudal M, Monash J, Zhang L, Wen J, Mysore KS, Macknight R, Putterill J (2013) Overexpression of Medicago SVP genes causes floral defects and delayed flowering in Arabidopsis but only affects floral development in Medicago. J Exp Bot 65:429-442

14. Jiang Y, Peng J, Zhang Z, Lin S, Lin S, Yang X (2019) The Role of EjSVPs in Flower Initiation in Eriobotrya japonica. Int J Mol Sci 20: 5933

15. Lee S, Choi SC, An G (2008a) Rice SVP-group MADS-box proteins, OsMADS22 and OsMADS55, are negative regulators of brassinosteroid responses. The Plant J 54: 93-105

16. Lee J, Oh M, Park H, Lee I (2008b) SOC1 translocated to the nucleus by interaction with AGL24 directly regulates LEAFY. The Plant J 55: 832-43

17. Lee JH, Park SH, Ahn JH (2012) Functional conservation and diversification between rice OsMADS221 
18. OsMADS55 and ArabidopsisSVP proteins. Plant Sci 185: 97-104

19. Lee JH, Ryu H-S, Chung KS, Posé D, Kim S, Schmid M, Ahn JH (2013) Regulation of Temperature-

20. Responsive Flowering by MADS-Box Transcription Factor Repressors. Science 342: 628-632

21. Li D, Liu C, Shen L, Wu Y, Chen H, Robertson M, Helliwell CA, Ito T, Meyerowitz E, Yu H (2008) A Repressor Complex Governs the Integration of Flowering Signals in Arabidopsis. Dev Cell 15: 110120

22. Li ZM, Zhang JZ, Mei L, Deng XX, Hu CG, Yao JL (2010) PtSVP, an SVP homolog from trifoliate orange (Poncirus trifoliata L. Raf.), shows seasonal periodicity of meristem determination and affects flower development in transgenic Arabidopsis and tobacco plants. Plant Mol Biol 74: 129-

23. 142

24. Lin SY, Mao GX (2007) The habit and regeneration of bamboo flowering (In Chinese). For Sci Technol 32: $23-25$

25. Liu S, Qi T, Ma J, Ma T, Ma L, Lin X (2016) Ectopic expression of a SOC1 homolog from Phyllostachys violascens alters flowering time and identity of floral organs in Arabidopsis thaliana. Trees 30: 2203-2215

26. Liu C, Xi W, Shen L, Tan C, Yu H (2009) Regulation of Floral Patterning by Flowering Time Genes. Dev Cell 16: 711-722

27. Livak KJ, Schmittgen TD (2001) Analysis of Relative Gene Expression Data Using Real-Time Quantitative PCR and the $2^{-\triangle \Delta C T}$ Method. Methods 25: 402-408

28. Ma JJ, Liu SN, Zhu LF, Qi TT, Lin XC (2016) Cloning and functional analysis of VRN1 gene from

29. Phyllostachys violascens (In Chinese). Journal of nuclear agricultural sciences 30: 1699-1705

30. Marín-González E, Matías-Hernández L, Aguilar-Jaramillo AE, Lee JH, Ahn JH, Suárez-López P, Pelaz S (2015) SHORT VEGETATIVE PHASE Up-Regulates TEMPRANILLO2 Floral Repressor at Low Ambient Temperatures. Plant Physiol 169: 1214-1224

31. Masiero S, Li M-A, Will I, Hartmann U, Saedler H, Huijser P, Schwarz-Sommer Z, Sommer H (2004) INCOMPOSITA: a MADS-box gene controlling prophyll development and floral meristem identity in Antirrhinum. Development 131: 5981-5990

32. Mateos JL, Madrigal P, Tsuda K, Rawat V, Richter R, Romera-Branchat M, Fornara F, Schneeberger K, Krajewski P, Coupland G (2015) Combinatorial activities of SHORT VEGETATIVE PHASE and FLOWERING LOCUS C define distinct modes of flowering regulation in Arabidopsis. Genome Biol 16: 31

33. Michaels SD, Ditta G, Gustafson-Brown C, Pelaz S, Yanofsky M, Amasino RM (2003) AGL24 acts as a promoter of flowering in Arabidopsis and is positively regulated by vernalization. The Plant $\mathrm{J} 33$ : 867-874

34. Parcy F (2005) Flowering: a time for integration. Int J Dev Biol 49: 585-593

35. Peng Z, Lu Y, Li L, Zhao Q, Feng Q, Gao Z, Lu H, Hu T, Yao N, Liu K, Li Y, Fan D, Guo Y, Li W, Lu Y, Weng Q, Zhou C, Zhang L, Huang T, Zhao Y, Zhu C, Liu X, Yang X, Wang T, Miao K, Zhuang C, Cao X, Tang 
W, Liu G, Liu Y, Chen J, Liu Z, Yuan L, Liu Z, Huang X, Lu T, Fei B, Ning Z, Han B, Jiang Z (2013) The draft genome of the fast-growing non-timber forest species moso bamboo (Phyllostachys heterocycla). Nat Genet 45: 456-461

36. Qi FY; Hu T; Peng ZH; Gao J (2013) Screening of reference genes used in qRT-PCR and expression analysis of PheTFL1 gene in Moso Bamboo (In Chinese). Acta Bot Borea 33: 0048-0052

37. Sentoku N, Kato H, Kitano H, Imai R (2005) OsMADS22, an STMADS11-like MADS-box gene of rice, is expressed in non-vegetative tissues and its ectopic expression induces spikelet meristem indeterminacy. Mol Genet Genomics 273: 1-9

38. Sharma P, Dhanwantri K, Mehta S (2014) Bamboo as a building material. Int J Civ Eng 5: 249-254

39. Tamura K, Peterson D, Peterson N, Stecher G, Nei M, Kumar S (2011) MEGA5: Molecular Evolutionary Genetics Analysis Using Maximum Likelihood, Evolutionary Distance, and Maximum Parsimony Methods. Mol Biol Evol 28: 2731-2739

40. Tang X, Liang M, Han J, Cheng J, Zhang H, Liu X (2019) Ectopic expression of LoSVP, a MADSdomain transcription factor from lily, leads to delayed flowering in transgenic Arabidopsis. Plant Cell Rep 39: 289-298

41. Trevaskis B, Tadege M, Hemming MN, Peacock WJ, Dennis ES, Sheldon C (2006) Short Vegetative Phase-Like MADS-Box Genes Inhibit Floral Meristem Identity in Barley. Plant Physiol 143: 225-235

42. Wang J, Jiu S, Xu Y, Sabir IA, Wang L, Ma C, Xu W, Wang S, Zhang C (2021) SVP-like gene PavSVP potentially suppressing flowering with PavSEP, PavAP1, and PavJONITLESS in sweet cherries (Prunus avium L.). Plant Physiol Bioch 159: 277-284

43. Wang YC, Klein TM, Fromm M, Cao J, Sanford JC, Wu R (1988) Transient expression of foreign genes in rice, wheat and soybean cells following particle bombardment. Plant Mol Biol 11: 433-439

44. Wu RM, Walton EF, Richardson AC, Wood M, Hellens RP, Varkonyi-Gasic E (2011) Conservation and divergence of four kiwifruit SVP-like MADS-box genes suggest distinct roles in kiwifruit bud dormancy and flowering. J Exp Bot 63: 797-807

45. Wu R, Wang T, Warren BAW, Allan AC, Macknight RC, Varkonyi-Gasic E (2017) Kiwifruit SVP2 gene prevents premature budbreak during dormancy. J Exp Bot 68: 1071-1082

46. Yao W, Li C, Lin S, Ren L, Wan Y, Zhang L, Ding Y (2020) Morphological Characteristics and Transcriptome Comparisons of the Shoot Buds from Flowering and Non-Flowering Pleioblastus pygmaeus. Forests 11: 1229

47. Yoo SD, Cho YH, Sheen J (2007) Arabidopsis mesophyll protoplasts: a versatile cell system for transient gene expression analysis. Nature Protocols 2: 1565-1572

48. Zheng X, Lin S, Fu H, Wan Y, Ding Y (2020) The Bamboo Flowering Cycle Sheds Light on Flowering Diversity. Front Plant Sci 11: 381

49. Zhou FY, Yu Q, Zhang Y, Yao CC, Han YJ (2020) StMADS11 Subfamily Gene PfMADS16 From Polypogon fugax Regulates Early Flowering and Seed Development. Front Plant Sci 11: 525 
a

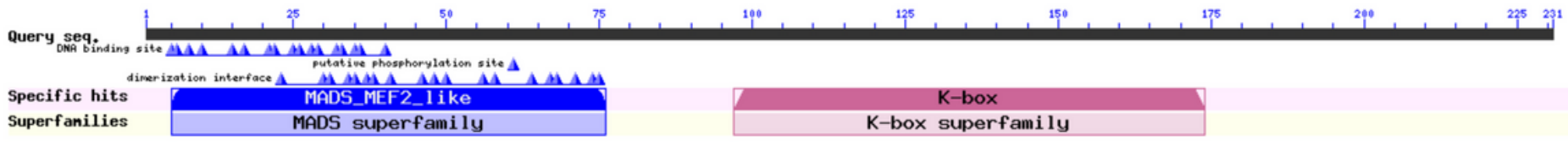

b

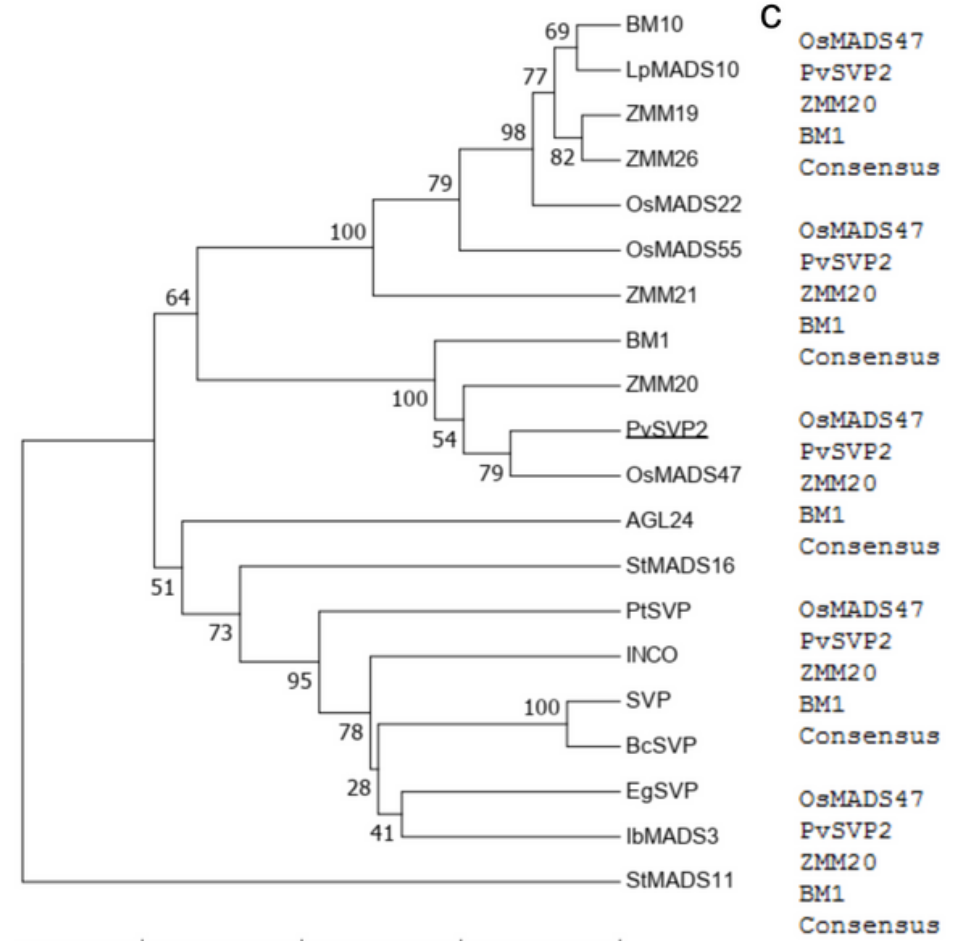

MAGGGGGGGRGEGEGRAATGKRERIAIRRIDNLAARQVTFSKRRPGIRK 50 $\ldots \ldots \ldots$ MAGKRERIAIRRIDSLAARQVTFSKRRRGIFRK 33

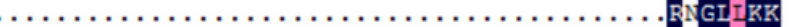
$\ldots \ldots \ldots \ldots$ MAGRRERIAIRRIENLAARQVTFSKRERGIFKK

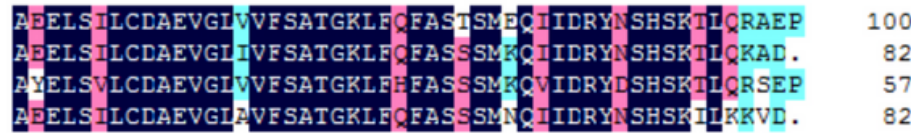
a els lcdaevgl vfsatgklf fas sm q idry shsk 1 SCIDICGE . DSSTCARLKEELAETSIRTRQMRGEELHRINV̈ELCELEKS 149 ELSHLDLHAEDSICARIREELAEPSIRIRQMRGEELHRINVCQLCDLEKS 132 CSSCICSHMDLGICARIKEELAETSIRIRQMRGEELQRISVEQLCDLEKT 107 EPSQIDLH . EDSNCARIRDELAEPSITICQMRGEEIQSINVCQLCZLEKS 131 SVLKTRSKR IIDE ID LDRRRM QL IEENIRLRECV SRMSRMËE LESGI GSVLK PRSCR IIDEIY LERKRMQL IEENSRLREQVARMSKMEMQ 182 LESGIGSVLKTRSQRIIDEISGLERKRT CLIEEN SRLREQVTRMSRMET. 156 LESGISSVLKIRS $\varnothing K I M$ I ISELEKKRVQL IEEN RLREQAS . . KMEMQ 178 lesgl svlk ks ki d i le kr qlieen rlkeq me QPGPDSEIVYEEGQSSESVTK ZSYPRPERENDYSSDTSIRLGIHS. . . 244 LGADS . EVVYEEGQSSESVTNZSYPRAPIDTEDSSDTSLRLGLPLFS 229 QLGADPE FVYEEGQSSESVTN ISYPRESTDTDLCSDTSIRLGIPLFSS 204 VAADPLVVVYDEGQSSESVTNISYPRPPIDTEDSSDTSIRLGISIFNS 226

Figure 1

Sequence analysis of PvSVP2. a Prediction of PvSVP2 by NCBI Conserved Domain database (https://www.ncbi.nlm.nih.gov/Structure/cdd/wrpsb.cgi). b Phylogenetic analysis of PvSVPs and their orthologs from other plant species. Amino acid sequences were aligned using Clustal W, and the tree was constructed using the neighbor-joining method by bootstrap with 1000 replicates in Mega 5.0. SVP-like proteins source and GenBank accession number: BM1: Hordeum vulgare (CAB97350); BM10: Hordeum vulgare (ABM21529); LpMADS10: Lolium perenne (AAZ17549); ZMM19: Zea mays (AJ430633); ZMM20: Zea mays (AJ430634); ZMM21: Zea mays (AJ430635); ZMM26: Zea mays (AJ430693); OsMADS22: 0. sativa (AB107957); OsMADS47 (AAQ23142): 0. sativa (AAQ23142); OsMADS55: 0. sativa (BAD35842); StMADS11: Solanum tuberosum (AAB94006); StMADS16: Solanum tuberosum (AAB94005); EgSVP: Eucalyptus occidentalis (AAP40641); AGL24: Arabidopsis thaliana (AEE84922); SVP: A. thaliana (NP_179840); BcSVP: Brassica rapa (DQ922945); INCO: Antirrhinum majus (CAG27846); IbMADS3: Ipomoea batatas (AAK27150); PtSVP: Citrus trifoliate (ACJ09170). c Multiple alignment of the deduced amino acid sequences of PvSVP2, BM1, ZMM20 and OsMADS47. 

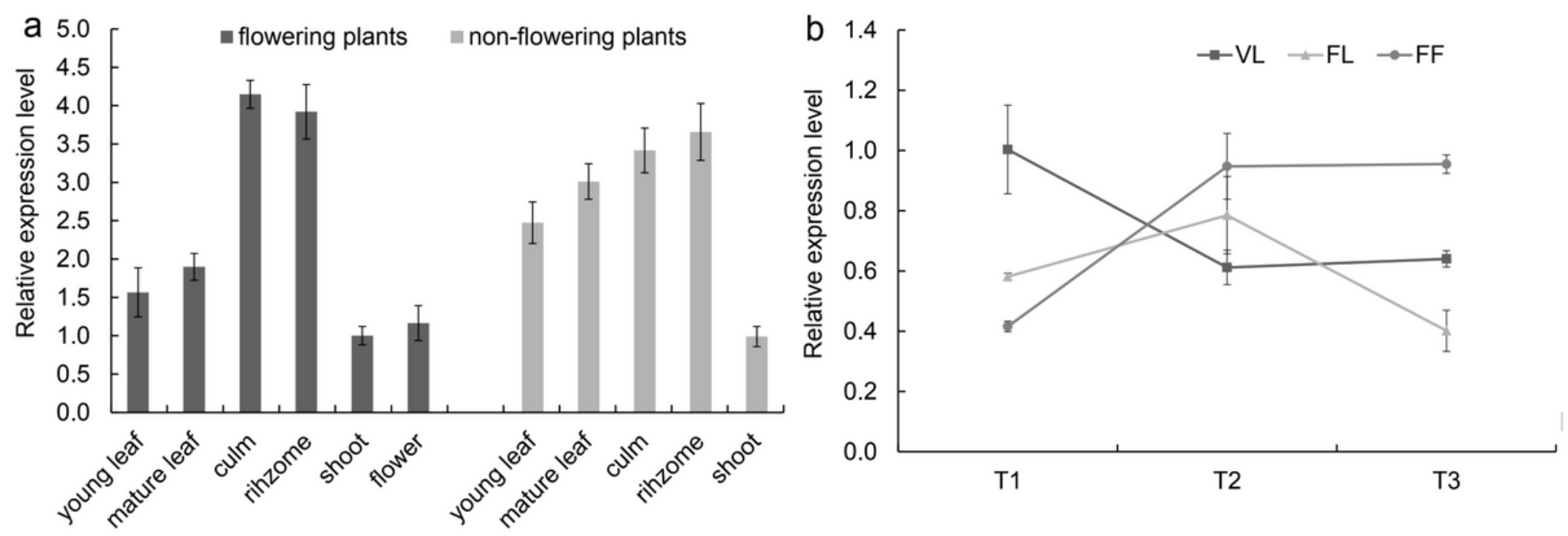

Figure 2

Tissue and temporal expression of $P V S V P 2$ in flowering and non-flowering $P$. violascens. a Relative expression of $P V S V P 2$ in different tissues. b Relative expression of $P V S V P 2$ in leaves of non-flowering plants $(\mathrm{VL})$, and flowering plants $(\mathrm{FL})$ and flowers (FF) of flowering plants during flower development. Data were mean \pm SE from three biological replicates. 

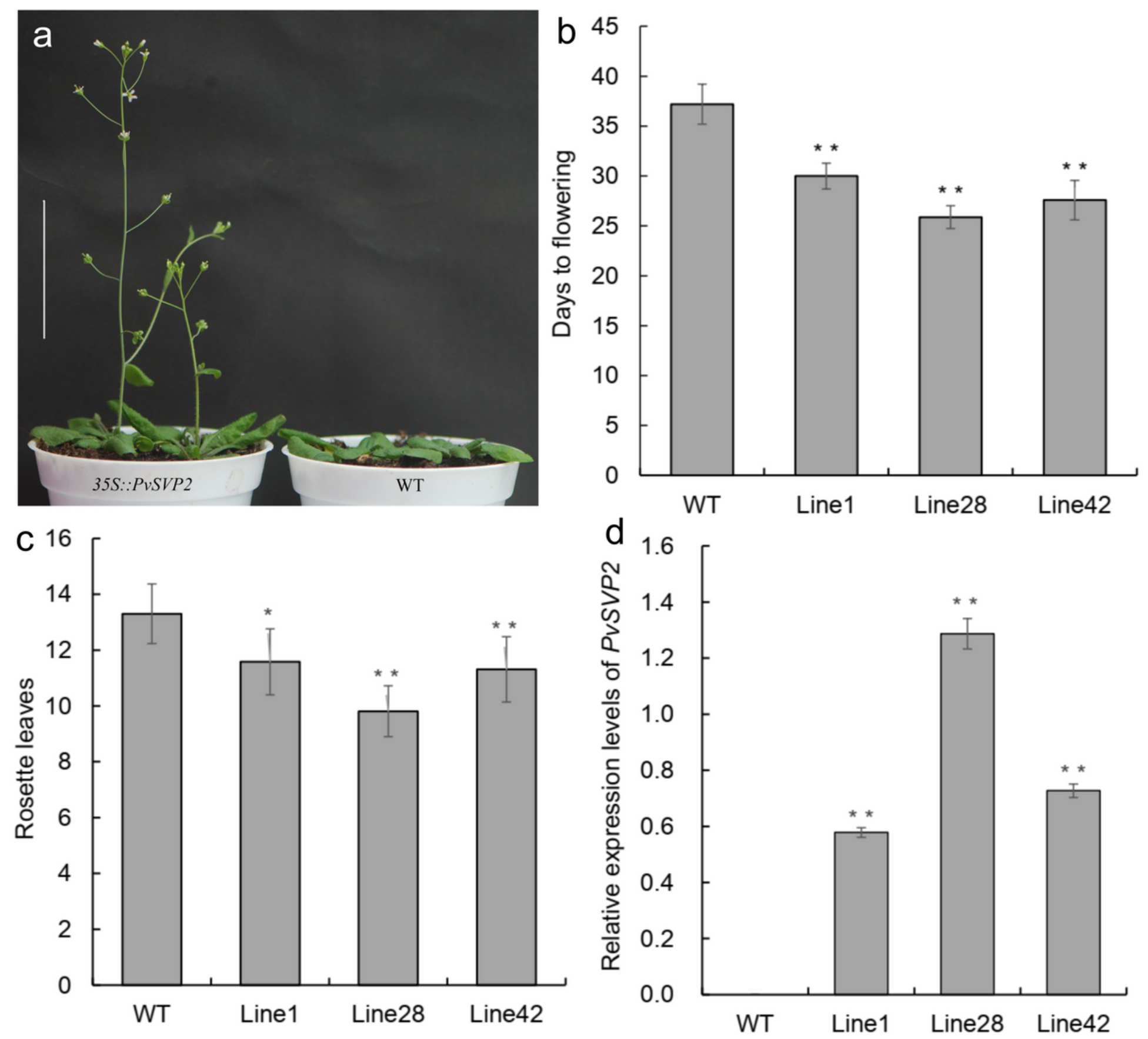

Figure 3

Phenotypic observations and qRT-PCR analysis between transgenic lines (1, 28 and 42) and wild-type (WT) A. thaliana plants. a The early flowering phenotype of 35S::PVSVP2 transgenic plants. $\mathbf{b}$ Days to flowering (c) number of rosette leaves. $\mathbf{d}$ Expression analysis of PVSVP2. Data were mean $\pm \mathrm{SE}$ from three biological replicates. Asterisks indicate significant differences between WT and transgenic plants, ${ }^{* *} p<0.05$ or ${ }^{* *} p<0.01$. The scale bar represents $5 \mathrm{~cm}$. 


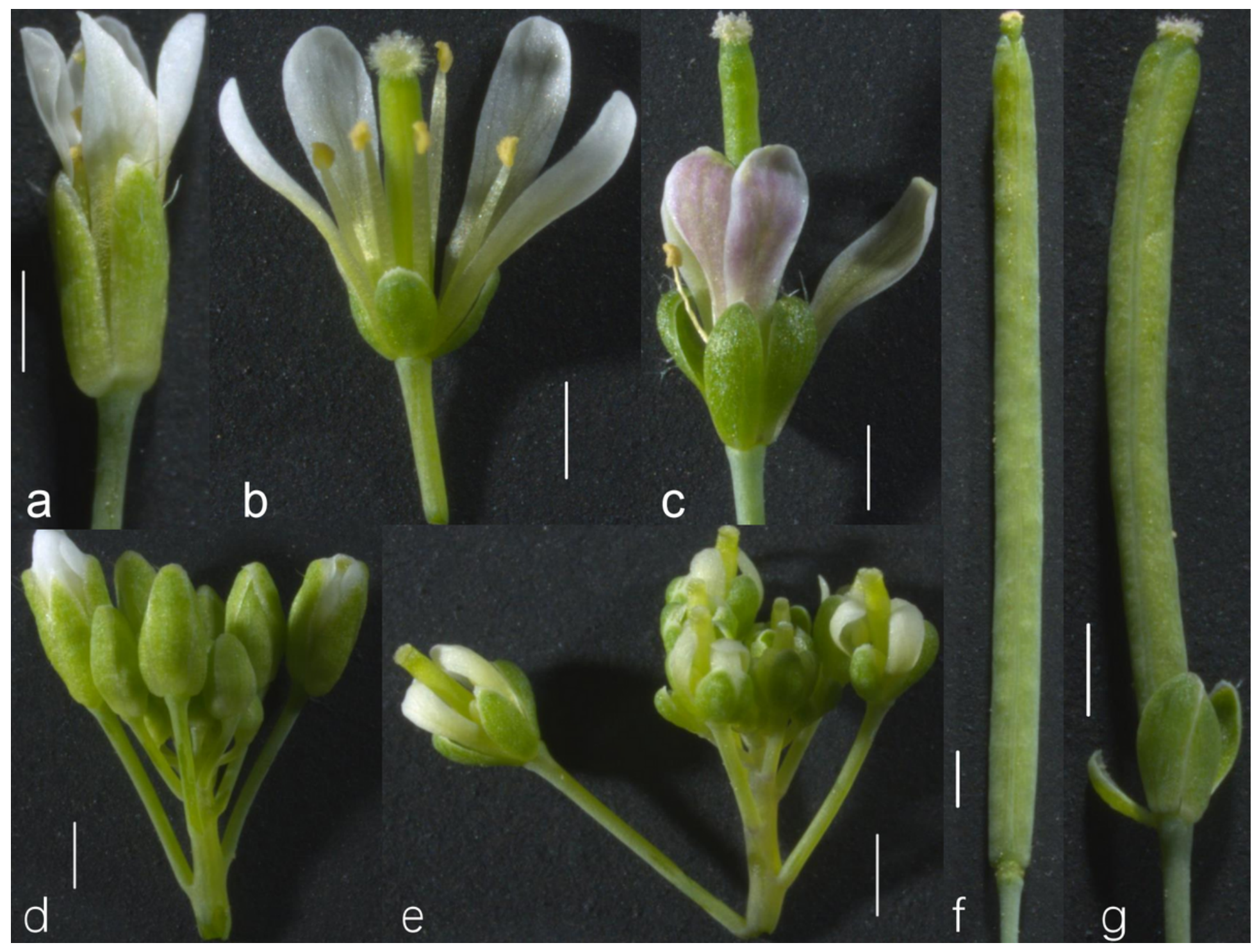

Figure 4

Flower morphology of wild-type (WT) and 35S::PVSVP2 transgenic A. thaliana plants. a WT Flower $\mathbf{b}$ and $\mathbf{c}$ transgenic flower $\mathbf{d}$ WT inflorescence $\mathbf{e}$ transgenic inflorescence $\mathbf{f}$ siliques of WT $\mathbf{g}$ siliques of the transgenic plant. The scale bars in Figure represent $1 \mathrm{~mm}$.

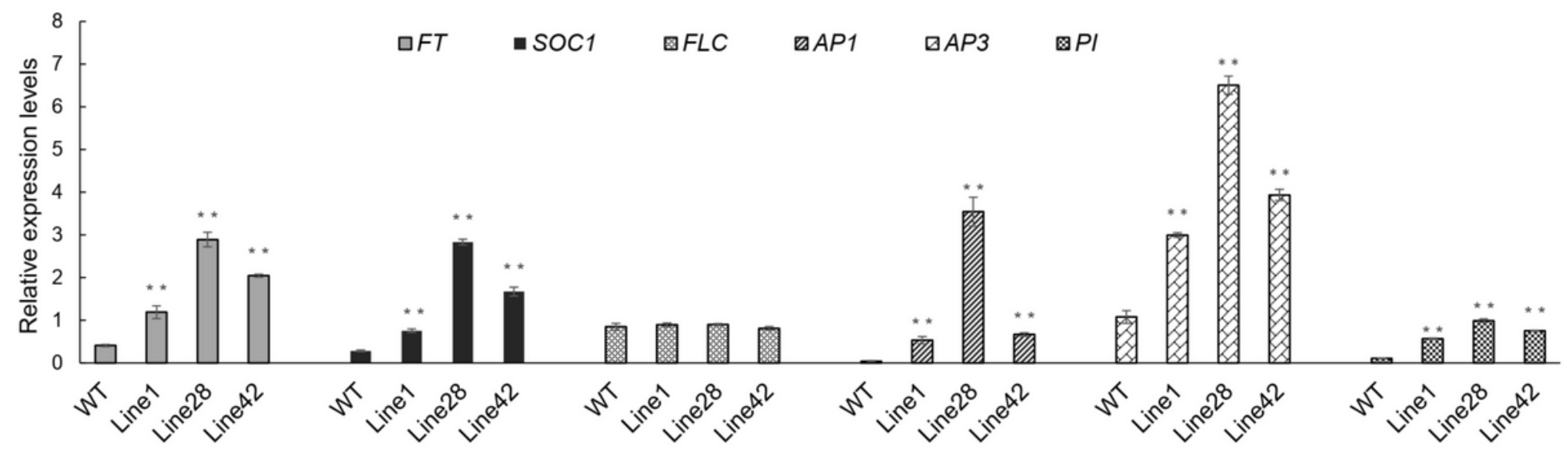

Figure 5 
The qRT-PCR results showed that the $F T$ and $S O C 1$ gene expression was significantly increased and positively correlated with PVSVP2 expression in transgenic lines.

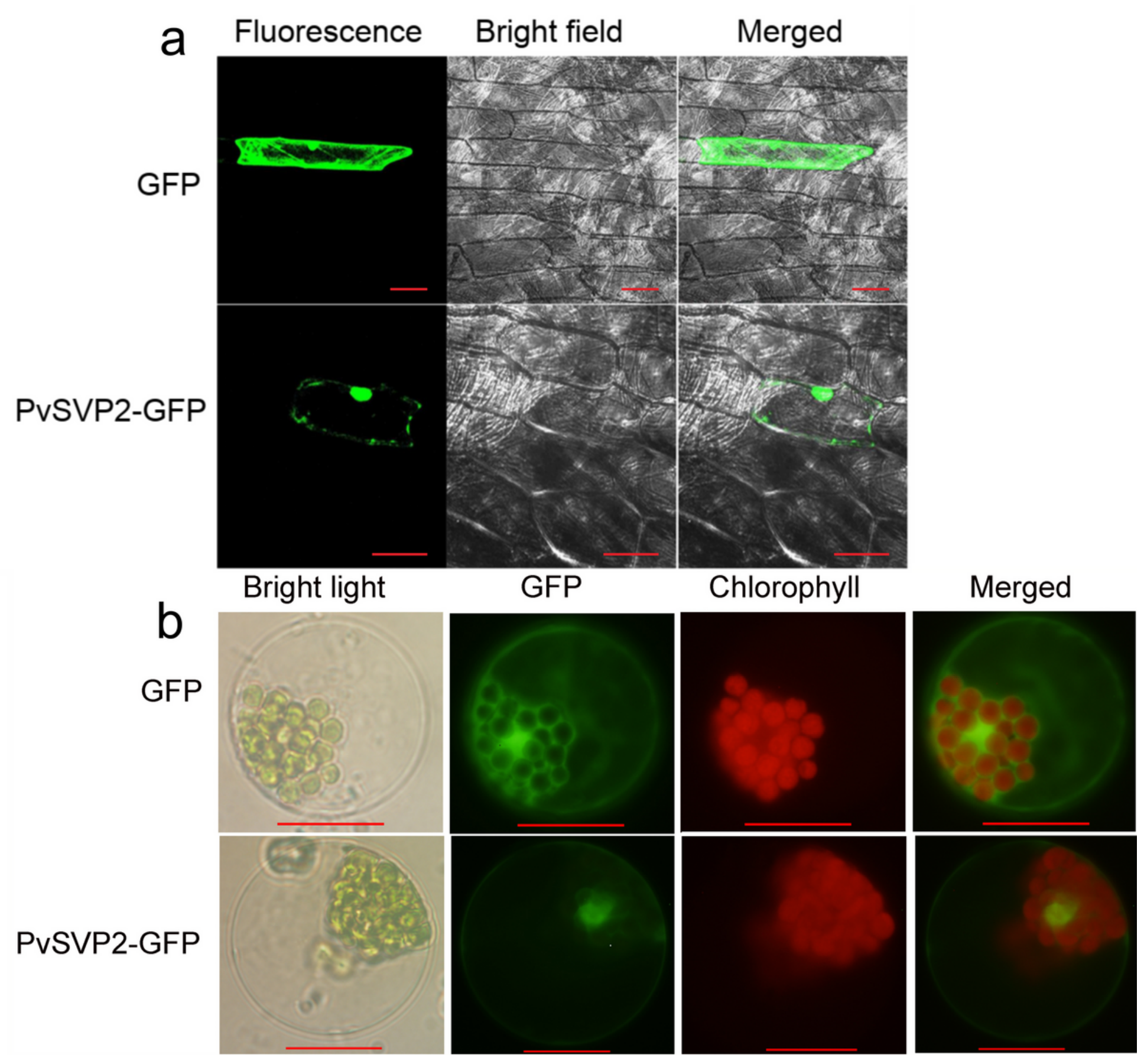

Figure 6

Subcellular location of GFP and PvSVP2-GFP protein in onion cells (a) and $A$. thaliana protoplasts (b). Bars represent $100 \mu \mathrm{m}$ (a) and $15 \mu \mathrm{m}$ (b), respectively. 


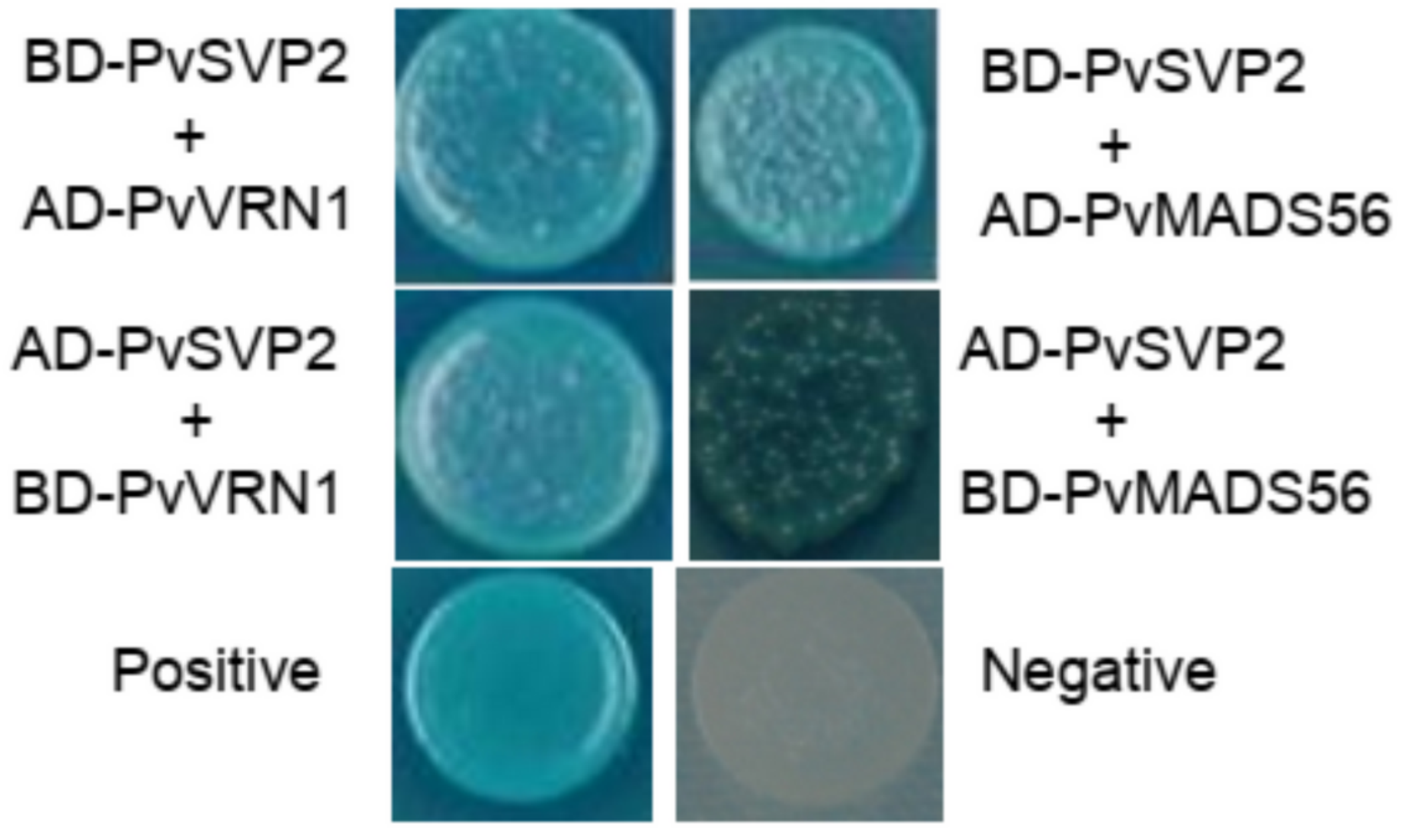

Figure 7

Interactions between PvSVP2 and PvMADS56 or PvVRN1 in yeast two-hybrid experiment. Yeast containing dual vectors of pGBKT7-53 and pGADT7-T was used as the positive control, that of pGBKT7Lam and pGADT7-T as the negative control. SD/-Leu/-Trp/-His/-Ade medium was used for clone selection purpose. Appearance of X-a-gal activity mirrors positive interaction. 


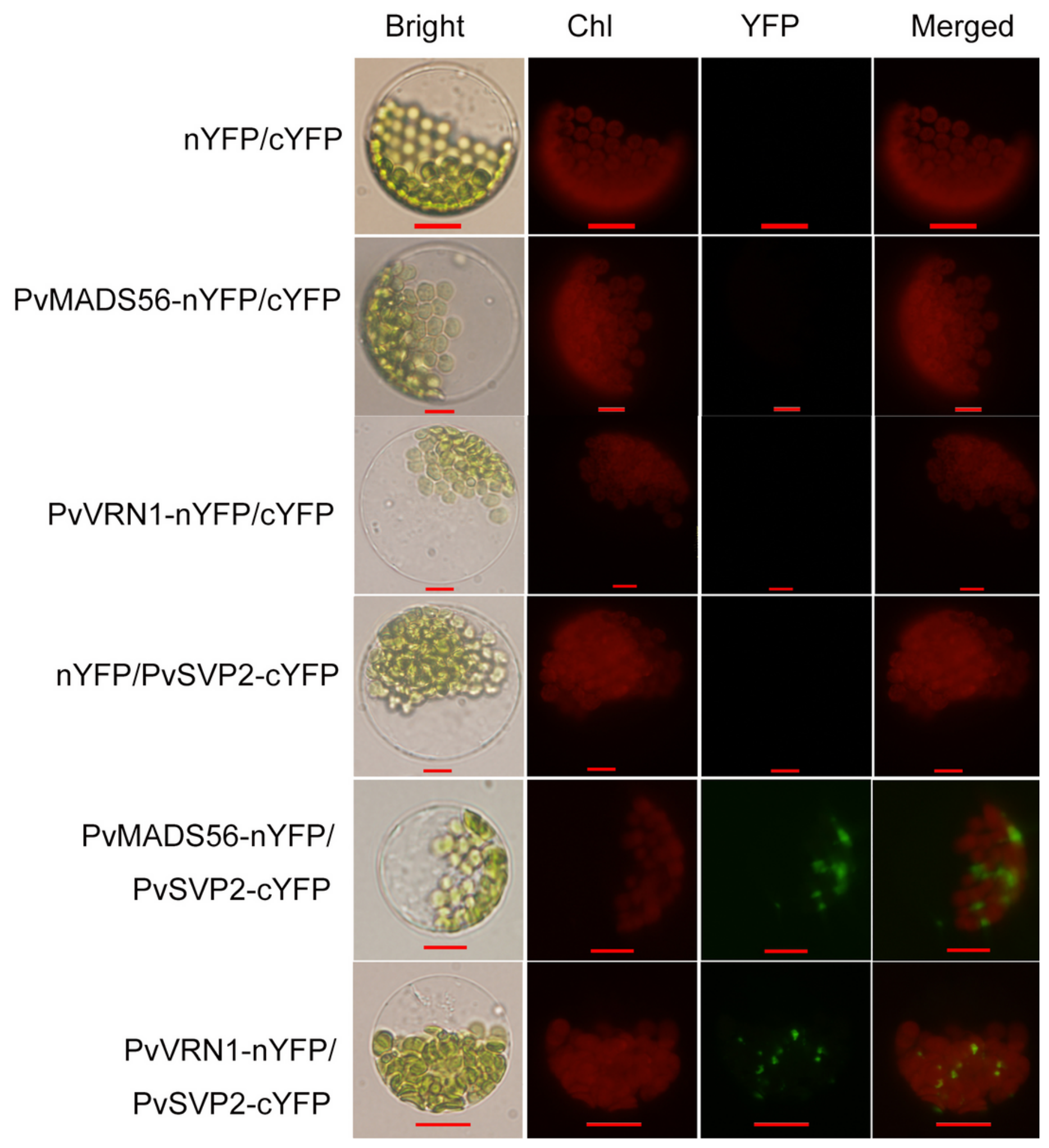

Figure 8

Interactions between PvSVP2 and PvMADS56 or PvVRN1 by BiFC assays. Images were captured 20-h after transient expression under an Olympus confocal microscope. Bars represent $15 \mu \mathrm{m}$. 

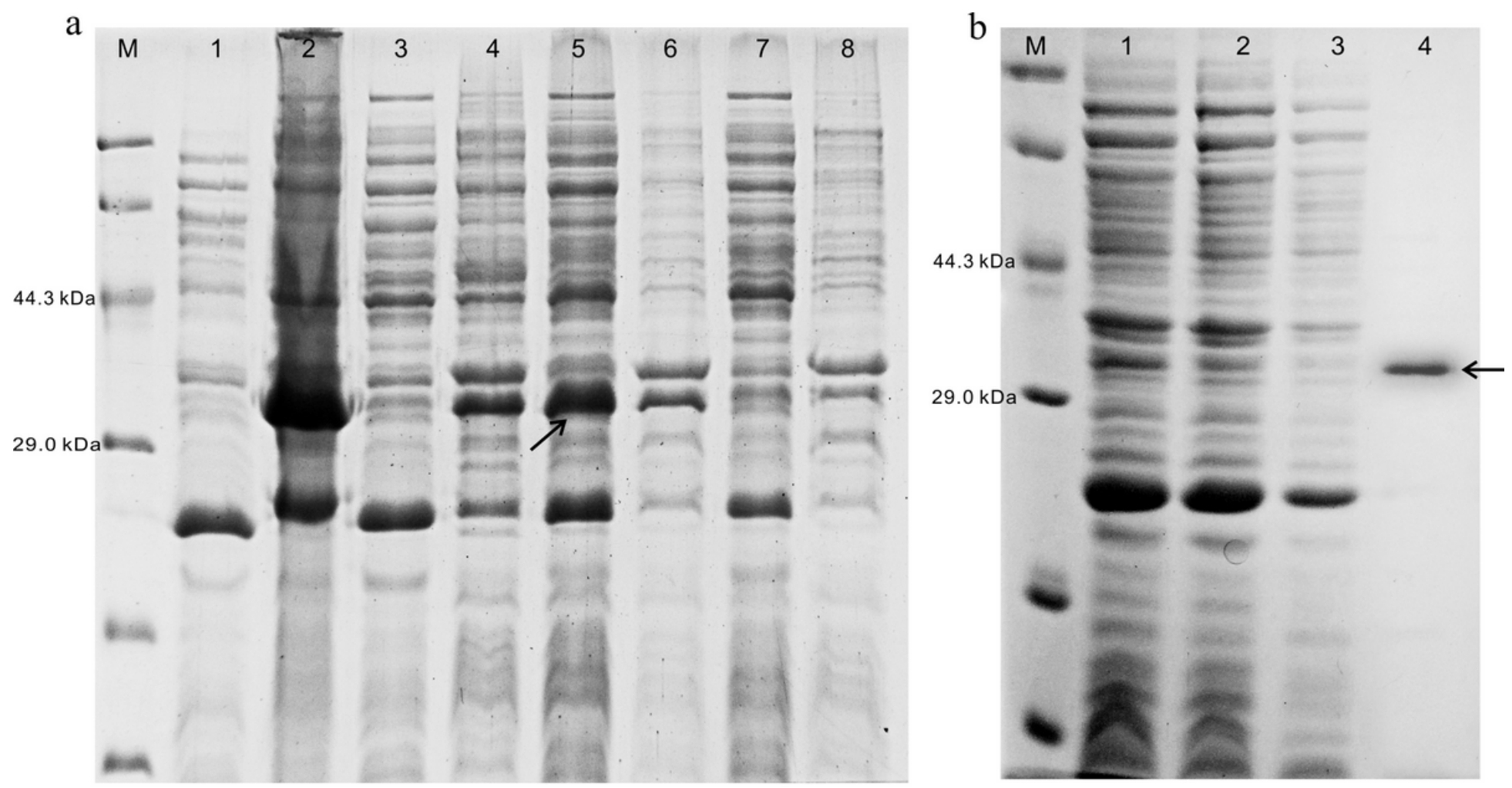

$\mathrm{C}$

1 MAGKRERIAI RRIDSLAARQ VTFSKRRRGL FKKAEELSIL CDAEVGLIVF

51 SATGKLFQFA SSSMKQIIDR YNSHSKTLQK ADELSHLDLH AEDSTCARLR

101 EELAEASLRL RQMRGEELHR LNVQQLQELE KSLESGLGSV LKAKSQKILD

151 EIYGLERKRM QLIEENSRLK EQVARMSKME MQLGADSEVV YEEGQSSESV

201 TNASYPRAPL DTEDSSDTSL RLGLPLFGSK

\section{Figure 9}

Prokaryotic expression and purification of PvSVP2. a SDS-PAGE analysis of PvSVP2 fusion protein in $E$. coli Rosetta (DE3) at $37^{\circ} \mathrm{C}$ and $20^{\circ} \mathrm{C}$. Lanes $1,2,3,4$ and lanes $5,6,7,8$ were respectively at $37^{\circ} \mathrm{C}$ and $20^{\circ} \mathrm{C}$; lanes 1, 2, 5, 6 represented the induction with IPTG; Ianes 3, 4, 7, 8 represented the induction without IPTG. M: marker; lanes 1, 3, 5, 7: supernatant; lanes 2, 4, 6, 8: precipitation. b Purification of PvSVP2. lane 1: uninduced; lane 2: supernatant after induction; lane 3: pellet after induction; lane 4: purified PvSVP2 fusion protein by a dextrin sepharose high performance medium. The arrows indicate the position of the fusion protein. c MALDI-TOF/TOF mass spectrometer analysis of PvSVP2 fusion protein. The tryptic peptides obtained by mass spectrometry are bold red.

\section{Supplementary Files}

This is a list of supplementary files associated with this preprint. Click to download.

- Fig.S1.jpg

- Tables1.docx 